\title{
Ultra-broadband Nonlinear Microwave Monolithic Integrated Circuits in SiGe, GaAs and $\ln P$
}

Krozer, Viktor; Johansen, Tom Keinicke; Djurhuus, Torsten; Jiang, Chenhui; Vidkjær, Jens

Published in:

International Conference on Microwaves, Radar \& Wireless Communications, 2006. MIKON 2006.

Link to article, DOI:

10.1109/MIKON.2006.4345336

Publication date:

2006

Document Version

Publisher's PDF, also known as Version of record

Link back to DTU Orbit

Citation (APA):

Krozer, V., Johansen, T. K., Djurhuus, T., Jiang, C., \& Vidkjær, J. (2006). Ultra-broadband Nonlinear Microwave Monolithic Integrated Circuits in SiGe, GaAs and InP. In International Conference on Microwaves, Radar \& Wireless Communications, 2006. MIKON 2006. IEEE. https://doi.org/10.1109/MIKON.2006.4345336

\section{General rights}

Copyright and moral rights for the publications made accessible in the public portal are retained by the authors and/or other copyright owners and it is a condition of accessing publications that users recognise and abide by the legal requirements associated with these rights.

- Users may download and print one copy of any publication from the public portal for the purpose of private study or research.

- You may not further distribute the material or use it for any profit-making activity or commercial gain

- You may freely distribute the URL identifying the publication in the public portal 


\title{
Ultra-broadband Nonlinear Microwave Monolithic Integrated Circuits in SiGe, GaAs and InP
}

\author{
Viktor Krozer, Tom K. Johansen, Torsten Djurhuus, Chenhui Jiang and Jens Vidkjær \\ Technical University of Denmark, Oersted•DTU, Department of Electromagnetic Systems, \\ Oersteds Plads 348, 2800 Kgs. Lyngby, Denmark, Phone:+45-45253769, E-mail:vk@oersted.dtu.dk
}

\begin{abstract}
Analog MMIC circuits with ultra-wideband operation are discussed in view of their frequency limitation and different circuit topologies. Results for designed and fabricated frequency converters in SiGe, GaAs, and InP technologies are presented in the paper. RF type circuit topologies exhibit a flat conversion gain with a $3 \mathrm{~dB}$ bandwidth of $10 \mathrm{GHz}$ for SiGe and in excess of $20 \mathrm{GHz}$ for GaAs processes. The concurrent LO-IF isolation is better than $-25 d B$, without including the improvement due to the combiner circuit. The converter circuits exhibit similar instantaneous bandwidth at IF and RF ports of $>7.5 \mathrm{GHz}$ and $>10 \mathrm{GHz}$ for SiGe BiCMOS and GaAs MMIC, respectively. Analysis of the frequency behaviour of frequency converting devices is presented for improved mixer design. Millimeter-wave front-end components for advanced microwave imaging and communications purposes have also been demonstrated. Analysis techniques and novel feedback schemes show improvement to the traditional circuit design. Subharmonic mixer measurements at $50 \mathrm{GHz}$ RF signal agree very well with simulations, which manifests the broadband operating properties of these circuits.
\end{abstract}

\section{INTRODUCTION}

Ultra-wideband circuits have become increasingly important in microwave imaging and communications. Ultra-wideband circuits are necessary for improved spatial resolution and enable spectral recognition in the case of microwave imaging systems. They also provide increased channel capacity and improved environmental immunity. One of the key technologies for advanced ultra-wideband $\mathrm{RF}$ front-ends is monolithic microwave integrated circuit (MMIC) technology employing SiGe BiCMOS, GaAs HEMT and at higher frequencies InP HBT or HEMT technologies. They are especially useful for modular design [1], [2]. The components under investigation include up/down converters, modulators, demodulators, baluns, buffer combiners, and amplifiers. All these components should operate with high amplitude and phase linearity and high dynamic range, which are a prerequisite for microwave imaging systems and wideband communication systems systems [3]-[6].

We have presented a number of solutions for ultrawideband components for microwave imaging systems, in particular concentrating on wideband frequency converters using RF circuit topologies. This is partially due to the fact that amplifiers utilizing differential amplifier stages, based on SiGe and GaAs MMICs, have previously been reported [7]-[12] with a wideband flat gain characteristics. We could demonstrate that very broadband analog MMIC circuits can be realized with both $\mathrm{SiGe}$ and GaAs technologies [13]-[16]. We could also demonstrate the experimental verification of simulated results for a number of relevant components such as modulator and demodulator, down/up converters, buffer amplifiers, and baluns. Quadrature oscillators have been analyzed and designed by the authors in [17], [18], [19]

We summarize these results in this paper and provide some design insight into ultra-wideband frequency converters such as mixers. The availability of such MMICs reduces front-end complexity and enables spectral and architectural reuse of components, which is believed to be the key issue in future front-ends in terms for flexibility and cost effectiveness. In contrast to typical front-end configurations advanced modular $\mathrm{RF}$ front-ends consist of a wideband converting unit, which offers the possibility to perform I/Q modulation/demodulation in the digital domain. This situation is illustrated in figure 1. I/Q modulators and demodulators are not required for this case. This aspect is discussed in detail in [5].

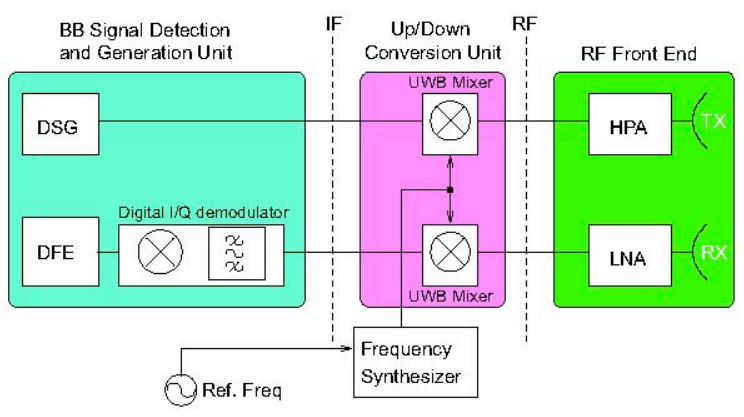

Fig. 1. Block diagram of a modular RF system.

The amplitude and phase performance required in microwave imaging systems converts to gain flatness over many decades for both amplifiers and mixers. For example, in a pulse compression SAR system the basic requirements are related to the impulse response obtained from a point target. In particular an amplitude ripple of less than $0.2 \mathrm{~dB}$ over a frequency band of $800 \mathrm{MHz}$ and a phase ripple of $\sim 5^{0}$ over the same frequency band is required for an accurate point target detection with low side-lobes in the compressed FM modulated pulse radar signal [4]. This means that the circuits to be designed should exhibit an instantaneous $3 \mathrm{~dB}$ bandwidth well above $10 \mathrm{GHz}$.

Millimeter-wave operation in the frequency range around $59-86 \mathrm{GHz}$ is particularly interesting for WLAN, automotive, and wireless gigabit networks. The frequencies around $60 \mathrm{GHz}$ exhibit very strong attenuation due to atmospheric losses, whereas the losses at $80-86 \mathrm{GHz}$ are 
very moderate and communication systems with several kilometers range and gigabit transmission capacity are feasible. An additional advantage is the large (5 GHz) instantaneous allocated frequency band, which allows for very wideband channels. It has also an advantage in microwave imaging in terms of improved resolution and better visibility than the $94 \mathrm{GHz}$ band. A simplified block diagram for a millimeter-wave front-end is illustrated in figure 2. Subharmonic operation is chosen due to the difficulties in providing LO power at these frequencies.

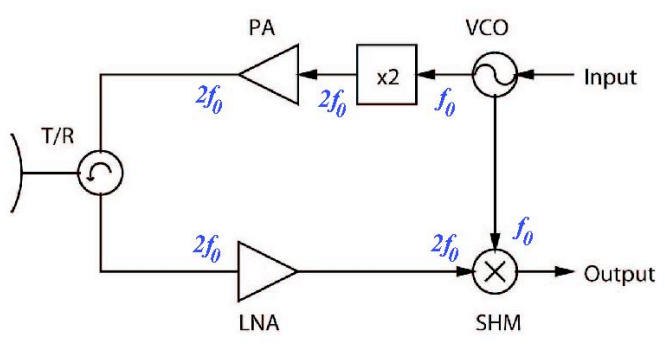

Fig. 2. Simplified block diagram of a millimeter-wave front-end.

The paper discusses original designs for a frequency doubler and subharmonic mixer designed to operate in the $\mathrm{V}$ band. Measurement results and circuit analysis is presented based on analytical formulation of the frequency doubling operation. The measurements presented are at a lower frequency due to limitations in current measurement equipment.

\section{ULTRA-WIDEBAND MMIC FREQUENCY CONVERTER DESIGN AND ANALYSIS}

Microwave amplifiers based on differential stages can fulfill the strict specifications discussed in the introduction with the help of ultra-fast SiGe or GaAs MMIC processes and employing careful inductive peaking and feedback techniques, as indicated schematically in fig.3a). However, mixer circuits based on Gilbert cells, illustrated in fig. 3b), complying with the above requirements have been explored only recently. We present below analytical expressions for these circuits based on conversion matrix analysis in the case of mixers, and small-signal timevarying approach to identify the limiting mechanisms in broadband operation.

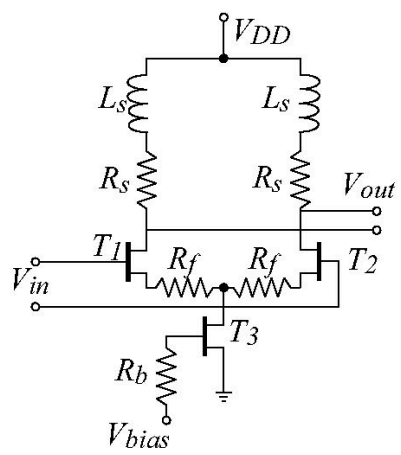

a)

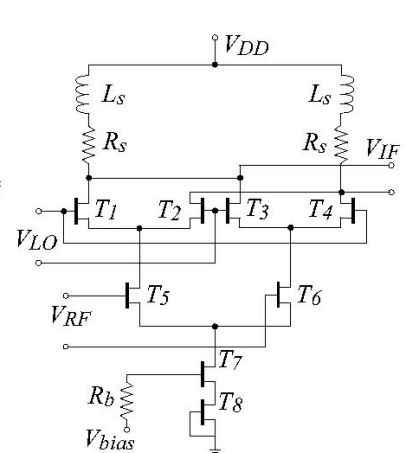

b)
Fig. 3. Basic circuits for differential amplifiers and mixers.
Previously reported integrated active mixers based on FET technologies, [10], [20], [21], have been optimized for down-conversion and exhibit narrowband IF bandwidth. In wideband applications mixers should be optimized for wideband operation at both the RF and IF ports in order to provide undistorted frequency conversion of wideband signals. Recently, we have derived analytical relations for the broadband operation of the Gilbert cell mixer based on HEMT devices [22]. This analysis is divided into two parts describing the switching quad and the transconductance stage. The analytical expression for the conversion gain of the Gilbert cell mixer is given by

$$
\begin{aligned}
G_{m i x} & =G_{t r} \times G_{s w}=\frac{2}{\pi} \frac{A}{B+j C} \cdot \frac{D}{E+F} \\
A & =R_{d s} G_{\max } R_{L} \\
B & =1+R_{d s} G_{\max }-R_{d s} R_{i} C_{g s 0} C_{d s 0} \omega_{r f}^{2} \\
C & =\omega_{r f}\left(C_{g s 0}\left(R_{i}+2 R_{d s}\right)+C_{d s 0} R_{d s}\right) \\
D & =g_{m \_t r} Z_{d s}-j \omega_{r f} C_{g s_{-} t r} R_{s_{-} t r} \\
E & =R_{s_{t} t r}\left(g_{m_{-} t r} Z_{d s}-j \omega_{r f} C_{g s \_t r} R_{s_{-} t r}\right) \\
F & =\left(j \omega_{r f} C_{g s_{-} t r}\left(R_{i_{-} t r}+R_{s_{-} t r}\right)+1\right)\left(R_{s_{-} t r}+Z_{d s}\right)
\end{aligned}
$$

Harmonic balance simulation is used to verify the analytical expression for the mixer conversion gain. Angelov model for GaAs HEMT is applied in the simulation as well as in the analytical expressions. Figure 4 presents a comparison between the theory described here and full harmonic balance simulations. It can be concluded from the figure that $C_{g} d$ has a large influence on the results, whereas the inclusion of the source series resistance is less critical.

A similar approach can be applied to HBT based circuits. The schematic of a mixer design which provides improved trade-off between conversion gain and port bandwidths is shown in fig. 5 .

A detailed small-signal time-varying analysis shows that the two main bandwidth limitations in the Gilbert cell mixer can be separated into limitations at the RF and IF port, respectively [23]. The $3 \mathrm{~dB}$ RF port bandwidth, $f_{R F,-3 d B}$, depends on the input bandwidth of the transistors in the transconductance stage as [23]

$$
f_{R F,-3 d B}=f_{T}\left(\frac{1}{\left(R_{b}+R_{e}\right) g_{m}}+\frac{g_{\pi}}{g_{m}}+\frac{R_{e}}{R_{b}+R_{e}}\right)
$$

where $f_{T}$ is the cut-off frequency, $g_{m}$ is the transconductance, $g_{\pi}$ is the input conductance, $R_{b}$ is the total base resistance and $R_{e}$ is the emitter resistance. In the limit of $R_{e} \rightarrow \infty$ the $3 \mathrm{~dB}$ RF port bandwidth approaches the cutoff frequency $f_{T}$, however the resulting conversion gain is reduced proportional to $R_{e}$. Thus the full bandwidth potential of a technology is not available for design. The $3 \mathrm{~dB}$ IF port bandwidth $\left(f_{I F,-3 d B}\right)$ depends on the timeconstant at the output as [23]

$$
f_{I F,-3 d B}=\frac{1}{C_{c s}\left(R_{s}+2 R_{c}+2 R_{L}\right)}
$$

where $C_{C S}$ is the collector-substrate capacitance, $R_{s}$ is the substrate resistance, $R_{c}$ is the collector resistance and $R_{L}$ 


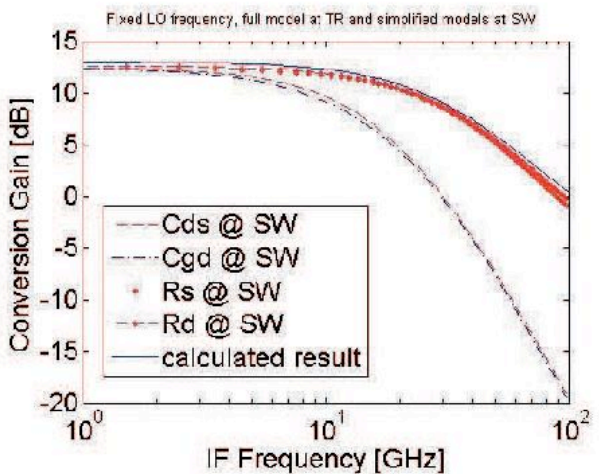

a)

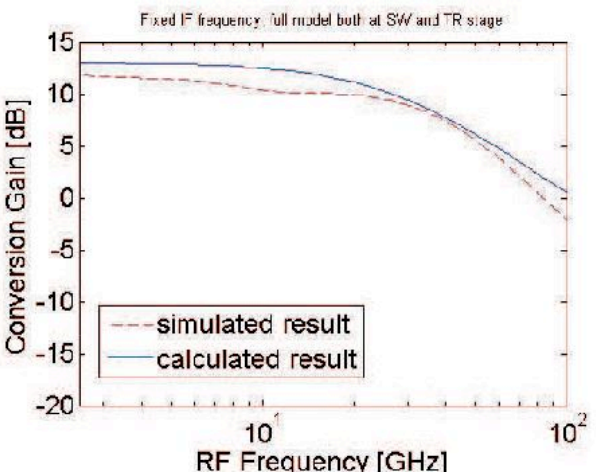

b)

Fig. 4. Comparison of calculated and simulated active Gilbert cell mixer's conversion gain. a) LO frequency is fixed at $2 \mathrm{GHz}$ and $C_{d s}$, $C_{g d}, R_{s}$ and $R_{d}$ of the transistors in switching quad are included in the simulation one by one. b) IF frequency is fixed at $0.5 \mathrm{GHz}$, and and $C_{d s}$, $C_{g d}, R_{s}$ and $R_{d}$ of the transistors in switching quad are all included in the simulation.

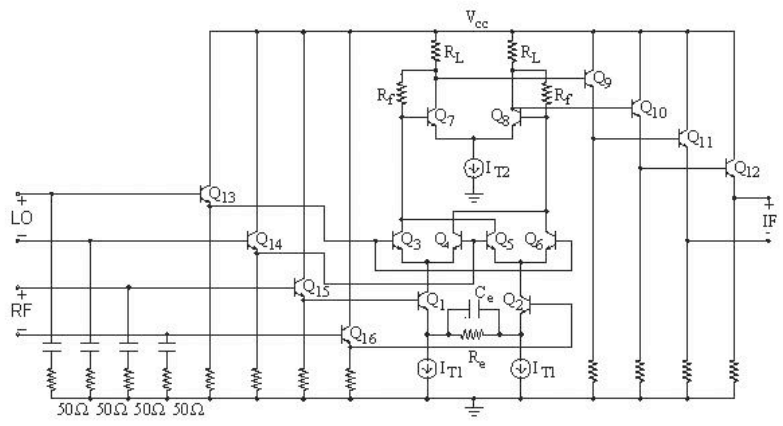

Fig. 5. Modified Gilbert Cell mixer topology.

is the Gilbert Cell load resistance. The IF port bandwidth may become the limiting factor in an $\mathrm{I} / \mathrm{Q}$ modulator if a high-IF frequency is chosen.

The Gilbert Cell mixer is modified for wideband performance by means of emitter (source) degeneration with capacitive peaking for the transconductance stage and a shunt feedback stage for the load circuit. The transconductance stage with emitter (source) degeneration allows a significant extension of the RF port bandwidth and can be optimized for conversion gain flatness and phase linearity. The shunt feedback stage provides a low impedance at the output node of the Gilbert Cell mixer, which increases the IF port bandwidth. Furthermore, the transfer function of the shunt feedback stage may exhibit two complex conjugated poles with possible improvement in IF port bandwidth by high-frequency peaking. Impedance match at the RF and LO port is provided by AC-coupled $50 \Omega$ shunt resistors.

Accurate choice of the individual transistors in the differential amplifier circuit and fast transistors are means of avoiding large inductance values, which are difficult to realize at mm-wave frequencies. In the differential stage based baluns, we utilize inductors of the order of $0.5 \mathrm{nH}$, which are easy to fabricate. It opens the possibility to address the millimeter-wave range with the currently available foundry processes. An accurate analysis employing EM simulation becomes mandatory in this frequency range.

\section{MMIC FOR ULTRA-WIDEBAND OPERATION}

\section{A. SiGe MMIC realizations}

In fig. 6 we present the photograph of a modulator/demodulator circuit using AMS 0.8um SiGe BiCMOS HBT technology together with experimental and simulated results. It is comprised of a Gilbert cell, baluns and buffers as building blocks of a quadrature modulator/demodulator. The distinctive feature of the modulator/demodulator circuit in fig. 6 is that both the IF and RF ports have almost identical wideband frequency characteristics. Therefore, such circuits can be employed in ultra-wideband applications or could be reused for different frequency bands.

When both RF and LO ports are swept in frequency with a fixed IF frequency of $0.4 \mathrm{GHz}$, a conversion gain of $8.5 \mathrm{~dB}$ and a $3 \mathrm{~dB}$ RF port bandwidth of $11 \mathrm{GHz}$ was achieved as shown in Fig. 6. The LO-IF isolation is better than $-25 \mathrm{~dB}$, as indicated in figure 7 , despite a singleended measurement condition for the modified Gilbert Cell mixer.

\section{B. GaAs MMIC realizations}

An example of a down-converter utilizing OMMIC ED02 GaAs process technology is shown in fig. 8. The conversion gain exhibits a ripple of $\pm 0.25 \mathrm{~dB}$ over a very large frequency range up to around $6 \mathrm{GHz}$. The down-converter exhibits $10 \mathrm{~dB}$ gain with a noise figure of approximately $\mathrm{NF}=12 \mathrm{~dB}$ and fulfill the requirements for amplitude and phase linearity as specified above. Input matching in the circuit of fig. 8 is achieved with a common-gate FET active balun [4]. The GaAs MMIC exhibit slightly wider bandwidth as compared to the $\mathrm{SiGe}$ HBT technology. They also exhibit a larger dynamic range. Differential stage balun design is based on same principles as the Gilbert cell mixer. Therefore, the same considerations apply with regards to wideband operation.

A very broad bandwidth balun, as compared with fig. 6 , has been achieved with the OMMIC D01MH GaAs process, due to faster transistors and lower parasitic feedback capacitances [13]. The phase imbalance for these circuits is less than $\pm 2^{\circ}$ over the overall frequency range. The phase linearity is $5^{0}$ in the frequency range.

A down-converter in GaAs technology has been designed and can be depicted in fig. 9 with a $3 \mathrm{~dB}$ bandwidth 
a)

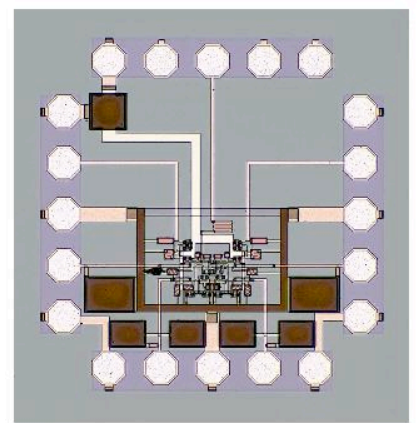

b)

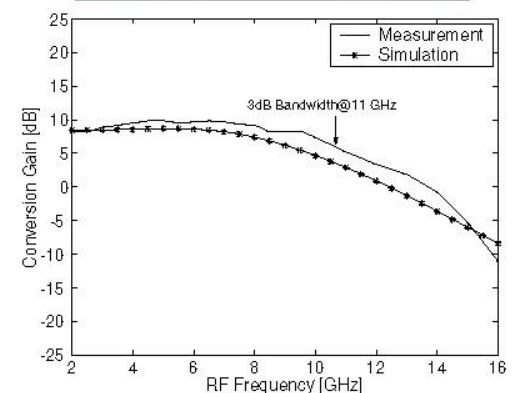

c)

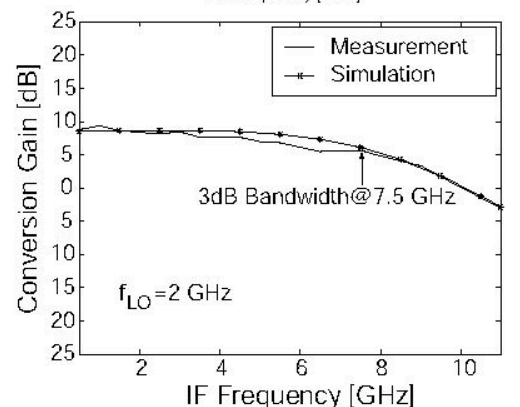

Fig. 6. SiGe HBT modulator/demodulator MMIC: a) Photograph of the chip, b) conversion gain versus RF frequency, and c) conversion gain versus IF frequency. Simulated results are symbols, measurements are solid lines.

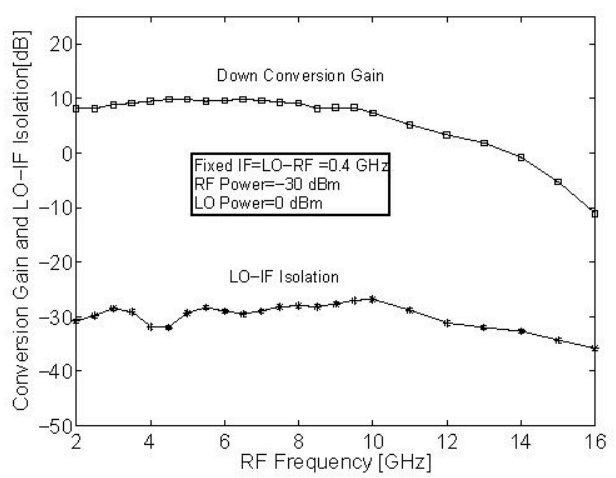

Fig. 7. Conversion gain and LO-IF isolation versus RF frequency for the circuit in fig. 6.

approaching $20 \mathrm{GHz}$, exhibiting a total area of $1 \times 2 \mathrm{~mm}$ including pads, a Gilbert cell core, and a fully differential active output combiner.

A flat gain response in excess of $11 \mathrm{GHz}$ is determined from simulations and measurements with a $3 \mathrm{~dB}$ bandwidth in excess of $17 \mathrm{GHz}$. The RF port conversion bandwidth was measured by sweeping both the RF and a)
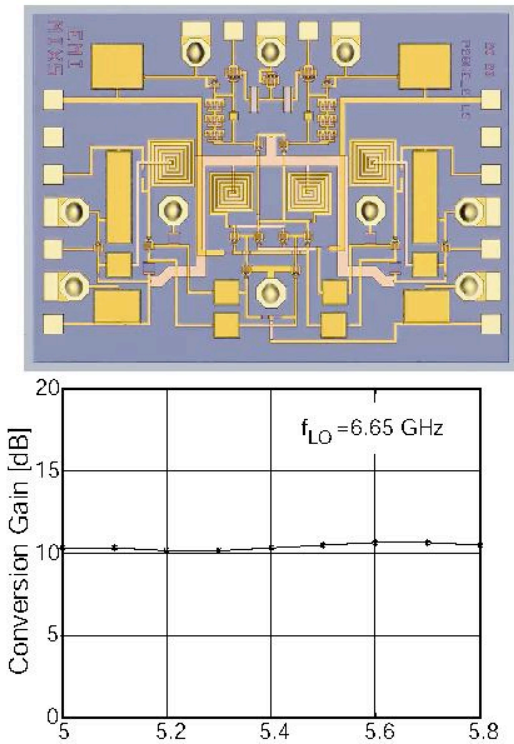

b)

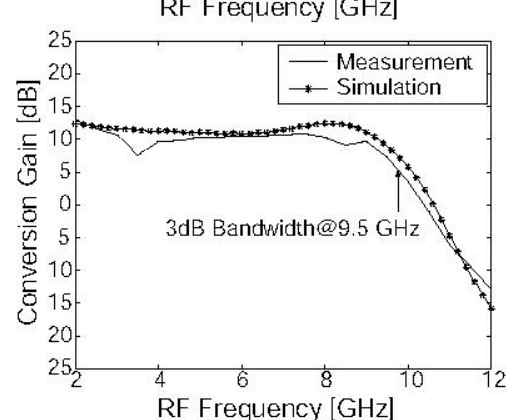

c)

Fig. 8. GaAs down-converter MMIC in ED02 technology a) chip photograph and b) measured results for conversion gain versus $R F$ frequency at C-band, and c) conversion gain characteristic as a function frequency for the RF port. The $\mathrm{LO}$ frequency is $6.65 \mathrm{GHz}$ with a power level of $\sim 0 \mathrm{dBm}$.

LO signals at a constant IF frequency of $1.2 \mathrm{GHz}$. It has been found that the inductor and resistor value can be decreased when a diode level shifter is employed as part of the load of the Gilbert cell output transistors. The required LO power has been simulated to be of the order of $10 \mathrm{dBm}$ and the $1 \mathrm{~dB}$ compression point is at $-10 \mathrm{dBm}$ $\mathrm{RF}$ power. The noise figure has not been optimized and is therefore rather high, with a value of $\mathrm{NF}=17 \mathrm{~dB}$.

\section{MMIC FOR MM-WAVE OPERATION}

Millimeter-wave MMIC frequency conversion circuits have been designed using InP HBT technology. This paper presents preliminary results on frequency doubling and a subharmonic mixer. The HBT frequency doubler design is based on a novel second harmonic feedback network. A simplified nonlinear analysis using harmonicbalance technique is performed to estimate the optimum excitation for HBT frequency doubler performance. It turns out to be a signal containing a second harmonic component which must be generated by feeding part of the second harmonic output signal back to the input. This excitation can be derived analytically if a pure sinusoidal excitation is assumed at the internal base- 
a)
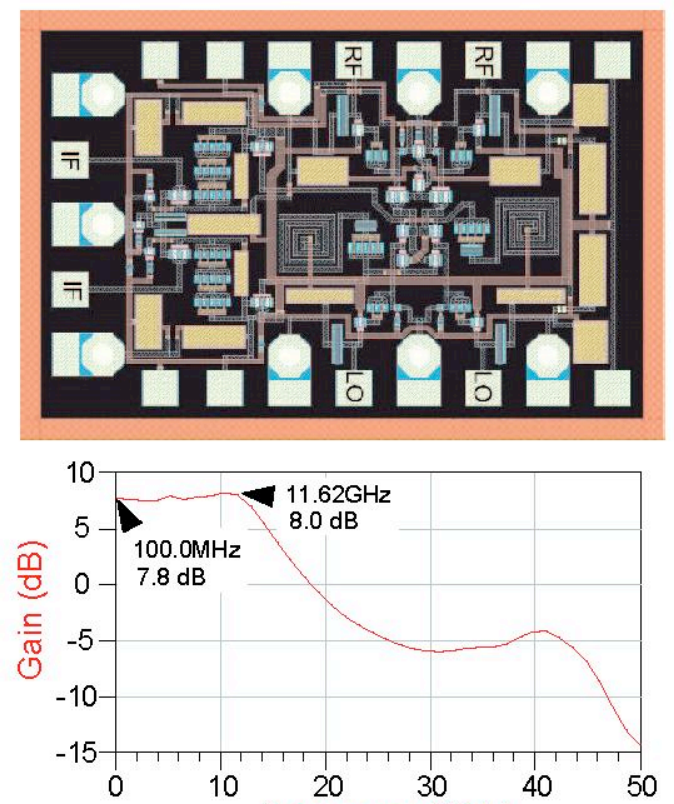

b)

c)

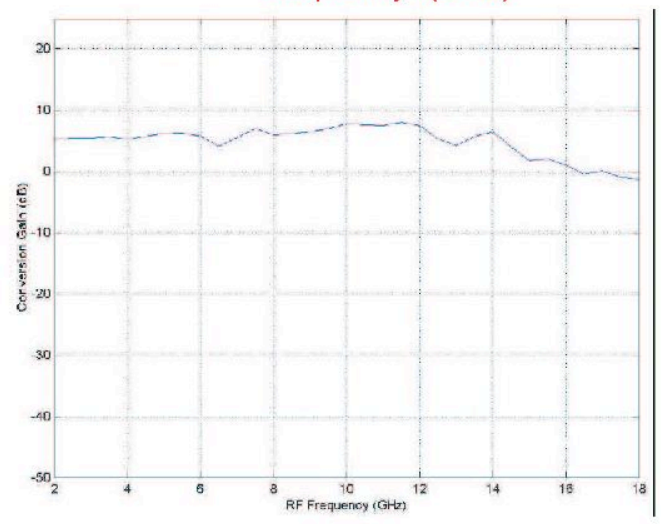

Fig. 9. GaAs down-converter MMIC in OMMIC D01MH GaAs technology a) chip layout, b) simulated and c) measured conversion gain versus RF frequency.

emitter junction. The frequency doubler including the novel second harmonic feedback network is shown in Fig. 10. The parallel tuned circuit assures maximum isolation between input and output of $Q_{1}$ for the fundamental frequency signal and presents a pure reactance at the second harmonic. This reactance forms a voltage divider together with the input matching network at the second harmonic. Preliminary on-wafer measurements have been performed on the fabricated circuit. The benefits of the second harmonic feedback network is evident in the output power versus control voltage shown in Fig. 11. In this figure a rise in output power of $2.5 \mathrm{~dB}$ is observed when the second harmonic feedback network is active. For a properly operating HBT frequency doubler the expected increase in output power is more than $6 \mathrm{~dB}$.

The subharmonic mixer necessary to downconvert the double frequency signal using fundamental frequency oscillator has been designed in the same process. The microphotograph of the fabricated frequency doubler is shown in Fig. 12. The chip size with pads is $1.4 \times 1.6$

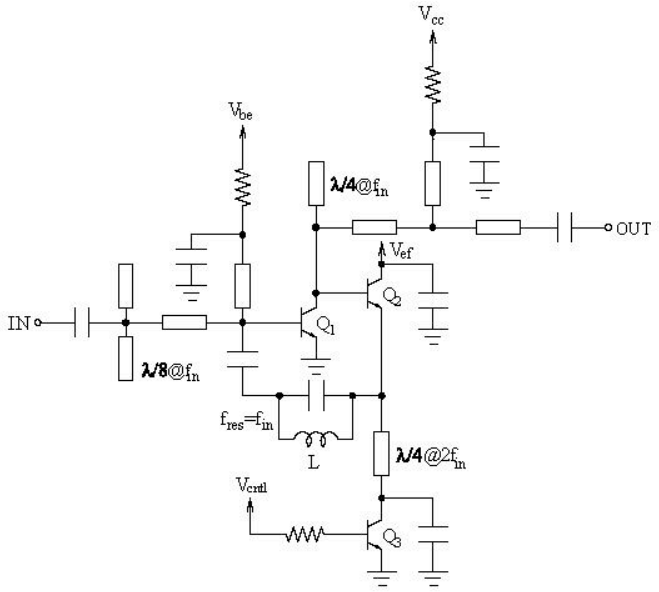

Fig. 10. Schematic of frequency doubler including second harmonic feedback network.

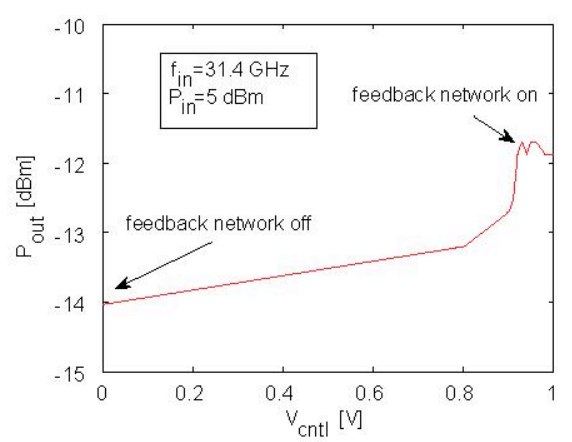

Fig. 11. Second harmonic output power versus control voltage.

$m m^{2}$. The subharmonic mixer has been designed for 41 $\mathrm{GHz} \mathrm{LO}$ frequency and $82 \mathrm{GHz} \mathrm{RF}$ input signal. The operating voltage is $2.5 \mathrm{~V}$ and the total current is around $63 \mathrm{~mA}$.

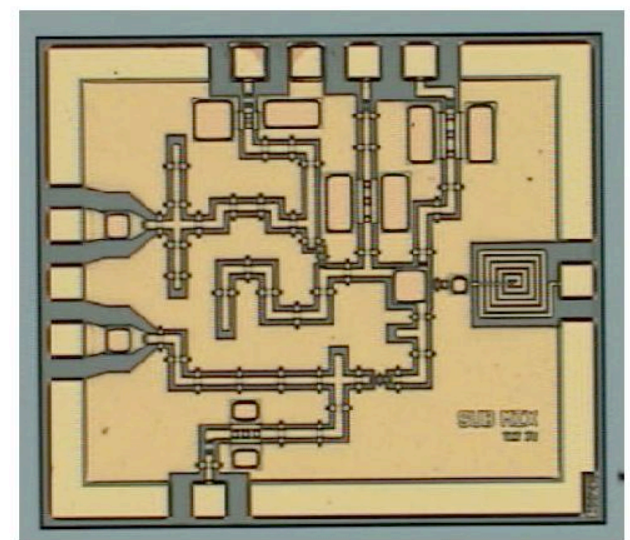

Fig. 12. Microphotograph of the subharmonic mixer. $\left(1.4 \times 1.6 \mathrm{~mm}^{2}\right.$ with pads).

The subharmonic mixer measurements have been limited by the measurement equipment available and therefore measurements at an LO frequency of $27 \mathrm{GHz}$ with an IF frequency of $2.5 \mathrm{GHz}$ have been performed and 
the conversion gain versus the RF frequency is presented in figure 13. Also included in the figure are predictions using harmonic balance techniques. It can be seen that the circuit operates satisfactory with a good agreement between simulated and measured results.

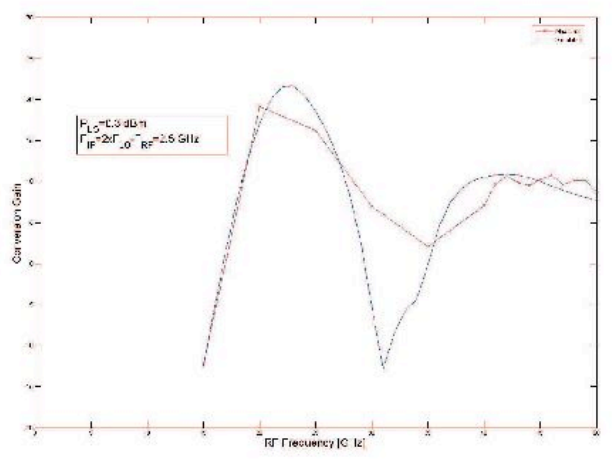

Fig. 13. Conversion gain of the subharmonic mixer versus the RF frequency.

\section{CONCLUSIONS}

Analog MMIC circuits with ultra-wideband operation have been discussed in view of their frequency limitation and different circuit topologies. Results for designed and fabricated frequency converters in $\mathrm{SiGe}, \mathrm{GaAs}$, and $\mathrm{InP}$ technologies have been presented. RF type circuit topologies exhibit a flat conversion gain with a $3 \mathrm{~dB}$ bandwidth of $10 \mathrm{GHz}$ for $\mathrm{SiGe}$ and in excess of $20 \mathrm{GHz}$ for $\mathrm{GaAs}$ processes. The concurrent LO-IF isolation is better than $-25 d B$, without including the improvement due to the combiner circuit. The converter circuits exhibit similar instantaneous bandwidth at IF and RF ports of $>7.5 \mathrm{GHz}$. For wideband applications such circuits are reducing the complexity of RF front-ends and exhibit fewer bandwidth limiting components.

Millimeter-wave front-end components for advanced microwave imaging and communications purposes have been demonstrated. Analysis techniques and novel feedback schemes show improvement to the traditional circuit design. Subharmonic mixer measurements at $50 \mathrm{GHz}$ RF signal agree very well with simulations, which manifests the broadband operating properties of these circuits.

\section{REFERENCES}

[1] F. A. Petz, J. Rosello-Guasch, C. Mavrocordatos, and C. V. Narasimha Rao, "Modular Deisgn of SAR Electronics," IEEE Trans. Microwave Theory and Techniques, vol. Vol. 47, no. 12 , pp. $2220-7,1999$.

[2] M. W. van der Graaf, M. van Wanum, A. P. M. Maas, E. M. Suijker, A. Knight, and M. Ludwig, "L-Band MMICs for SpaceBased SAR System," in 11th GAAS Gallium Arsenide and Compound Semiconductor Symp., 2003, pp. 173-8.

[3] E. L. Christensen, N. Skou, J. Dall, K. Woelders, J. H. Jorgensen, J. Granholm, and S. N. Madsen, "EMISAR: An Absolutely Calibrated Pol arimetric L- and C-band SAR," IEEE Trans. Geoscience and Remote Sensing, vol. 36, no. 6, pp. 1852-1865, Nov. 1998.

[4] T. K. Johansen, J. Vidkjær, and V. Krozer, "Ultra-wideband MMICs for remote sensing applications," in Proc. 2003 European Microwave Conference, München, Germany, Oct., 2003.
[5] E. Linzt Christensen, S. N. Madsen, and N. Skou, "Review of the Homodyne Technique for Coherent Radar," in IEEE Int. Radar Conference, 1990 , pp. 159-163.

[6] E. Lintz Christensen (ed), J. H. Joergensen, J. Dall, F. Hoeg, S. N. Madsen, J. Vidkjaer, J. Granholm, T. K Johansen, N. Skou, and K. Woelders, "'SAR+ System Design Report"," Tech. Rep. R 693, Technical University of Denmark, Dept. of Electromagnetic Systems, Jan. 2000.

[7] K.W. Kobayashi et al., "A DC-20 GHz InP HBT Balanced Analog Multiplier for High-Data-Rate Direct-Digital Modulation and Fiber-Optic Receiver Applications," IEEE Transaction on Microwave Theory and Techniques, vol. 48, no. 2, pp. 194-202, Feb. 2000.

[8] J. Glenn et al., "12-GHz Gilbert Mixers using a Manufacturable $\mathrm{Si} / \mathrm{SiGe}$ Epitaxial-Base Bipolar Technology," in IEEE BCTM, 1995, pp. 186-189.

[9] K. Osafune and Y. Yamauchi, "20-GHz 5-dB-Gain Analog Multipliers with $\mathrm{AlGaAs} / \mathrm{GaAs}$ HBT's," IEEE Transaction on Microwave Theory and Techniques, vol. 42, no. 3, pp. 518-520, Mar. 1994.

[10] C.F. Campbell and J.M. Beall, "'Design and Performance of a Highly Integrated Wideband Active Downconverter MMIC"," in IEEE Radio Frequency Integrated Circuits Symp., 2001.

[11] H.-M. Rein and M. Moller, "Design Considerations for Very-HighSpeed Si-Bipolar ICs Operting up to $50 \mathrm{~GB} / \mathrm{s}$," IEEE J. SolidState Circuits, vol. Vol. 31, no. 8, pp. 1076-1090, Aug. 1996.

[12] H. Kamitsuna and H. Ogawa, "Ultra-Wideband MMIC Active Power Splitters with Arbitrary Phase Relationships," IEEE Trans. Microwave Theory and Techniques, vol. Vol. 41, no. 9, pp. 15191523 , Sept 1993.

[13] V. Krozer, T. K. Johansen, T. Djurhuus, and J. Vidkjær, "Wideband Monolithic Microwave Integrated Circuit Frequency Converters with GaAs mHEMT Technology," in 2005 Proc. European Microwave Conf., nov 2005, pp. 637-640.

[14] Tom K. Johansen, Viktor Krozer, and Jens Vidkjær, "Substrate Effects in Wideband SiGe HBT Mixer Circuits," in 2005 European Gallium Arsenide and other Compound Semiconductors Application Symposium, nov 2005.

[15] Tom K. Johansen, Jens Vidkjær, and Viktor Krozer, "Analysis and Design of Wide-Band SiGe HBT Active Mixers," vol. 53, no. 7, pp. 2389-2397, 2005.

[16] V. Krozer, T. K. Johansen, T. Djurhuus, and J. Vidkjær, "UltraWideband Monolithic Microwave Integrated Circuit Solutions in $\mathrm{SiGe}$ and GaAs Technology," in Proc. European Microwave Conf., Amsterdam, The Netherland, 2004, accepted.

[17] T. Djurhuus, V. Krozer, J. Vidkjær, and T. K. Johansen, "Nonlinear Analysis of a Cross-Coupled Quadrature Harmonic Oscillator," in Intern. Workshop on NonLinear Microwaves and Millimetre waves INMMTC, Roma, Italy, nov 2004.

[18] T. Djurhuus, V. Krozer, J. Vidkjar, and T.K. Johansen, "Trade-off between phase-noise and signal quadrature in unilaterally coupled oscillators," Microwave Symposium Digest, 2005 IEEE MTT-S International, pp. 883-886, 2005.

[19] T Djurhuus, V Krozer, J Vidkjaer, and T K Johansen, "Analog Circuits and Systems - Nonlinear Analysis of a Cross-Coupled Quadrature Harmonic Oscillator," IEEE Transactions on Circuits and Systems - I-Regular Papers, vol. 52, no. 11, pp. 2276-2285, 2005.

[20] S. Fujita, Y. Imai, Y. Yamane, and H. Fushimi, "DC-10GHz Mixer and Amplifier GaAs ICs for Coherent Optical Heterodyne Receiver"," in IEEE International Solid-State Circuits Conference, 1991, pp. 122-125.

[21] C.F. Campbell, "'A Wideband pHEMT Downconverter MMIC for Satellite Communication Systems"," in IEEE MTT-S Digest, 1998 , pp. 55-58.

[22] C. Jiang, T. K. Johansen, and V. Krozer, "Conversion Matrix Analysis of GaAs HEMT Active Gilbert Cell Mixers," in Intern. Workshop on NonLinear Microwaves and Millimetre waves INMMIC, Aveiro, Portugal, jan 2006.

[23] T. K. Johansen, Monolithic Microwave Integrated Circuits for Wideband SAR System, Ph.D. thesis, Technical University of Denmark, Kgs. Lyngby, Denmark, 2003. 